\title{
Does Practice Make Perfect?
}

\author{
A. M. Hogan, and D. C. Winter ${ }^{1}$ \\ Institute of Clinical Outcomes in Research and Education (ICORE), St. Vincent's University Hospital, Elm Park, Dublin 4, Ireland
}

\begin{abstract}
Extensive literature supports the correlation between surgical volume and improved clinical outcome in the management of various cancers. It is this evidence that has catalysed the creation of centres of excellence. However, on closer inspection, many of these studies are poor quality, low weight and use vastly heterogenous end points in assessment of both volume and outcome. We critically appraise the English language literature published over the last ten years pertaining to the volume outcome relationship in the context of cancer care. Future balanced unbiased studies may enable equipoise in planning international cancer management strategies.
\end{abstract}

Key Words: Cancer-Volume-Outcome.

No longer is there room for eminence-based complacency or misguided arrogance in healthcare delivery. The day of the autonomous clinician is gone with a vogue towards standardised, evidence-based clinical excellence. Cynics would erroneously attribute this to a parallel increase in litigation but increasing patient knowledge and expectations with a move toward subspecialisation are the main catalysts driving change. When offered operative intervention, the question frequently asked by the patient is "How many of these have you done before?" This article aims to critically analyse recent literature and explore the correlation between volume and clinical outcome in the context of cancer care.

\section{BACKGROUND}

Mortality rates are reported to be influenced by the number of particular operations performed in a given hospital or by a specific surgeon (i.e. outcomes are better in high-volume centres). In 1999, the US Na-

Published online January 29, 2008

Address correspondence and reprint requests to: D. C. Winter; E-mail: WinterD@indigo.ie

Published by Springer Science+Business Media, LLC $\odot 2008$ The Society of Surgical Oncology, Inc. tional Cancer Policy Board recommended that patients requiring complex procedures be transferred from low- to high-volume hospitals in its report entitled "Ensuring Quality Cancer Care". ${ }^{1}$ The following year, the Institute of Medicine held a workshop to discuss cancer care, publishing a document ("Interpreting the Volume-Outcome Relationship in the Context of Cancer Care"2) which concluded that existing evidence was strong enough to recommend the regionalisation of high-risk operations. Hence, the impact of volume on outcome has been assessed in several tumour types but the majority of data relates to gastrointestinal, hepatobiliary, urological, and breast cancers.

\section{THE LITERATURE}

Patients undergoing pancreatic and oesophageal procedures have lower operative mortality and shorter hospital stay in the hands of experienced surgeons in high-volume units. ${ }^{3}$ With regard to gastric cancer, the findings are less consistent. Some suggest that high-volume centres have lower in-house mortality $^{4}$ but no change in long-term survival. ${ }^{5}$ Various end points have been examined in colorectal cancer (Table 1). Schrang and Billingsley both 
TABLE 1. Colorectal cancer outcome: high-and low-volume units

\begin{tabular}{llll}
\hline & High volume & Low volume & Ref. \\
\hline APR versus LAR & $\downarrow$ APR & $\uparrow$ APR & Meyerhardt et al. ${ }^{19}$ \\
& $\uparrow$ LAR & $\downarrow$ LAR & \\
Sphincter preservation & $\uparrow \uparrow$ & $\downarrow$ & Purves et al. $^{20}$ \\
30-day postoperative mortality & $\leftrightarrow$ & Schrag et al. & \\
Survival (overall and cancer specific) & $\uparrow$ & Schrag et al. & \\
Permanent stoma formation & $\downarrow$ & $\downarrow$ & McGrath et al. $^{22}$ \\
Colonic pouch formation & $\uparrow$ & $\uparrow$ & McGrath et al. $^{22}$ \\
\hline
\end{tabular}

APR, abdominoperineal resection; LAR, low anterior resection.

$\uparrow$ increased, $\downarrow$ decreased, $\leftrightarrow$ no variation.

showed that it was surgeon-specific experience combined with multidisciplinary support rather than centre experience that afforded significant survival advantage. 6,7

Comprehensive albeit retrospective studies unequivocally state that patients who undergo radical prostatectomy at lower-volume institutions are at significant risk of requiring adjuvant therapy due to adverse surgical factors, prolonged hospital admission, increased hospital charges and postoperative complications. ${ }^{8}$ The hospital structure of high-volume units, including easy availability of consultative, diagnostic and ancillary services, were cited as likely contributors to the association between procedure volume and short-term cystectomy outcomes. ${ }^{9}$ A minimum case load of only 11 radical cystectomies per year was cited to be associated with the lowest mortality rate. ${ }^{10}$

Less certainty exists in relation to breast cancer but a variety of end points have been examined, including number of visits required to obtain a nonoperative diagnosis, mastectomy rates for $<15 \mathrm{~mm}$ tumours and rate of referral for adjuvant radiotherapy. ${ }^{11}$ Skinner et al. were adamant that volume alone could not be used as a surrogate for expertise but, like most studies, conceded that patients with breast cancer operated on in high-volume units compared to very low-volume units had better survival. However there is ambiguity surrounding the exact causal relationship: volume effect alone versus surgical skill versus appropriate use of adjuvant therapy. ${ }^{12}$

\section{THE FLAWS}

The majority of studies are poor quality, heterogenous and potentially flawed. Even the best literature stems from retrospective review of large databases which are up to $40 \%$ inaccurate ${ }^{13}$ and pertain to selected patient groups. Most papers are published from a few very high-volume US centres, thus introducing immediate potential for bias. No consis- tent end point is used and, incredibly, few studies explore cancer-specific outcomes. Mortality rates, when not corrected for comorbidities or stage at diagnosis, are poor surrogates for more robust comparators of volume-outcome analysis such as cancerspecific survival, patient satisfaction and quality of life.

American data cannot be used as a basis for the formation of European cancer strategies because so many inherent differences exist. These include earlier disease stage at time of operation (a function of screening), ${ }^{14}$ wide variance in population ${ }^{15}$ and socioeconomic status ${ }^{16}$ as well as insured versus noninsured outcomes. ${ }^{17}$ Comparison of very highvolume centres and very low-volume centres is as redundant as measuring revenue from a supermarket versus a corner store. Is it not intuitive that analysis of such extremes will yield vastly different results? Looking at the structure-process-outcome model, structure is relatively fixed (health service, institution) but process is entirely variable and volume is but one component of it. Therefore, in the absence of multivariable data, subgroup analysis is entirely inappropriate, rendering the aforementioned studies at best biased, at worst invalid.

\section{The Surgeon}

To identify procedure volume in a single institution is easy but not so for quantifying specific operations done by a single surgeon, many of whom practise in several centres. Without asking individuals to record caseload prospectively, obtaining accurate figures may be very difficult. Surely significant bias could occur in that those willing to share details of operations may be confident of their own justification in performing such procedures. Furthermore, who counts as more experienced: a mature surgeon who has performed two colonic resections a week for 20 years but now does only two a month or a younger, specialist trained surgeon who performs 


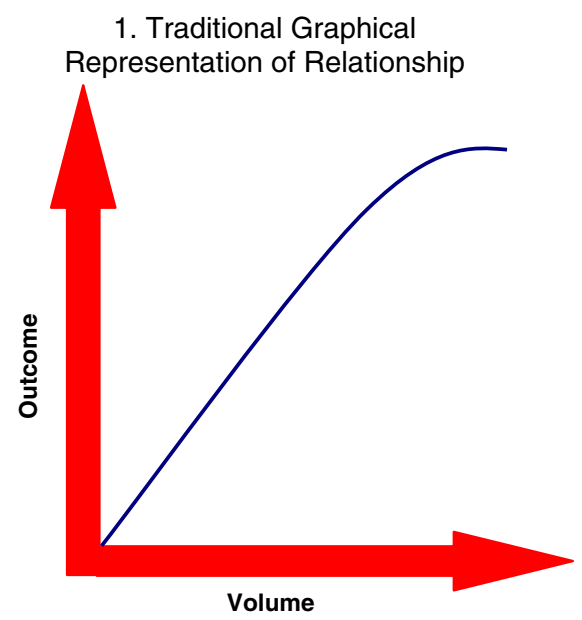

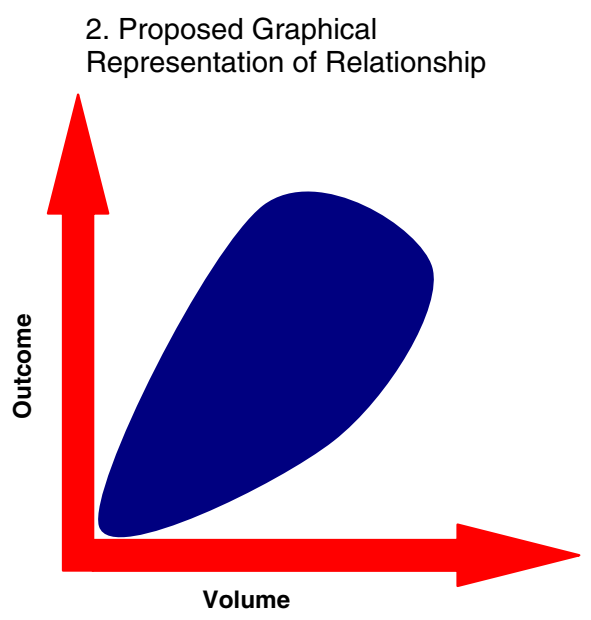

FIG. 1. Volume-outcome relationship. three a week? How do you weight lifetime experience against current volume? Should a centralised database of surgeons' logbooks exist, and should permission to operate be granted or denied based on this? What governing body should be afforded such a task? Should operating surgeons be ranked in their ability or would this border on defamation for the less fortunate ones? Regarding referral pattern, does volume attract quantity or do excellent clinicians attract patients? Many studies have compared the significance of surgeon experience to unit volume with varied conclusions as to which has more impact. Do excellent surgeons naturally aggregate in excellent high-volume units, thus giving a self-propagating explanation for improved outcome?

\section{The Institution}

Many papers allude to the importance of the multidisciplinary approach in cancer care. Highervolume units are far more likely to have subspecialised radiologists, radiation and medical oncologists, high dependency and intensive care units, cancer specialist nurses, dedicated psychologists and palliative care support. Anecdotally, the involvement of such services translates into better patient outcome regardless of unit volume, thus confounding results. The resounding evidence in favour of the volumeoutcome relationship pertains to those cancers requiring adjuvant therapy: oesophagus, pancreas and advanced colorectal. It seems, therefore, that good surgical technique or individual surgeon experience do not exclusively guarantee positive outcomes and that much depends on availability of radiation and medical oncology.
More often than not, within a short period of the introduction of a new service, its resources are saturated. At what point does a dedicated unit declare that available services can no longer provide for patient throughput? The worry is that potential exists for patients to receive suboptimal care just before this saturation point is reached (Fig. 1). Surely stretched resources in a high-volume centre are just as dangerous as absence of resources in smaller institution. A study on the difference in time lapse between diagnosis and intervention between institutions with different volumes would be welcome. Would prognosis be improved if a patient with aggressive disease underwent early intervention at a lower-volume centre rather than late intervention at a higher-volume centre? As cancer management is a dynamic process, the question of safety in transferring postoperative follow-up of a patient operated on in a high-volume unit to a less experienced lower-volume local centre is a pertinent one. On the other hand, should surgery be performed in low-volume units and adjuvant therapies in specialist centres? Without a doubt, the idea of hospital units functioning as a syncitium rather than single buildings must be engendered and skillappropriate tasks assigned to each component, as recommended in breast cancer management by the Clinical Oncology Information Network (COIN) group. ${ }^{18}$

\section{The Patient}

Quality of life and patient satisfaction, apart from in colorectal and prostate cancers, are largely ignored when assessing impact of volume on clinical outcome. Is it preferential for elderly patients to travel long distances for management of a low-grade tumour or 
would they be better served by treatment in a lowervolume local centre where follow-up will be on their doorstep? Decisions like this are made on a daily basis in the context of primary care and so this begs the question of higher-volume specialist centres receiving selected patient cohorts, thus falsely improving outcome. This is confirmed by Morris et al. who showed that patients treated in the Australian private sector were likely to be younger, male and to have an earlier disease stage. ${ }^{17}$

\section{THE FUTURE}

The literature supports a correlation between surgical volume and improved clinical outcome in cancer care. However, a rather simplistic approach is evident in many studies and much potential remains for unbiased, prospective, statistically sound investigations with the aim of numerically stratifying appropriate volume and its impact on disease specific cancer outcomes.

While traditionally graph 1 in Fig. 1 has been used to represent the volume-outcome relationship, it seems probable that it is more accurately represented by graph 2 in Fig. 1, and can be interpreted as an area under a curve rather than a strictly linear relationship.

\section{REFERENCES}

1. www.nap.edu/catalog.php?record_id $=6467$.

2. www.books.nap.edu/openbook.phb.

3. Birkmeyer JD, Warshaw AL, Finlayson SR, et al. Relationship between hospital volume and late survival after pancreaticoduodenectomy. Surgery 1999; 126:178-83.

4. Smith DL, Elting LS, Learn PA, et al. Factors influencing the volume outcome relationship in gastrectomies: a population based study. Ann Surg Oncology 2007; 14:1846-52.

5. Enzinger PC, Benedetti JK, Meyerhardt JA, et al. Impact of hospital volume on recurrence and survival after surgery for gastric cancer. Ann Surg 2007; 245:426-34.
6. Schrag D, Panageas KS, Riedel E, et al. Hospital and surgeon procedure volume as predictors of outcome following rectal cancer resection. Ann Surg 2002; 236:583-92.

7. Billingsley KG, Morris AM, Dominitz JA, et al. Surgeon and hospital characteristics as predictors of major adverse outcomes following colon cancer surgery: understanding the volume outcome relationship. Arch Surg. 2007; 142:23-31.

8. Ellison LM, Trock BJ, Poe NR, et al. The effect of hospital volume on cancer control after radical prostatectomy. J Urol 2005; 173:2094-8.

9. Hollenbeck BK, Daignault S, Dunn RL, et al. Getting under the hood of the volume-outcome relationship for radical cystectomy. J Urol 2007; 177:2095-9.

10. McCabe JE, Jibawi A, Javle P. Defining the minimal hospital case-load to achieve optimum outcomes in radical cystectomy. BJU Int 2005; 96:806-10.

11. Sainsbury R, Haward B, Rider L, et al. Influence of clinician workload and patterns of treatment on survival from breast cancer. Lancet 1995; 345:1265-70.

12. Skinner KA, Helsper JT, Deapen D. Breast cancer. Do specialists make a difference? Ann Surg Oncol 2003; 10(6):606-15.

13. Kelly M, Lamah M. Evaluating the accuracy of data entry into a regional colorectal cancer database: Implications for national audit. Colorectal Dis 2007; 9:337-9.

14. Colorectal Cancer Screening: Clinical guidelines and rationale. Winawer S. Gastroenterology 2003; 112(2):594-642.

15. Rosenberg NA, Pritchard JK, et al. Genetic structure of human populations. Science 2002; 298:2381-95.

16. Krieger N, Williams D, Moss N. Genetic structure of human populations. Measuring social class in US public health research; concepts, methodologies and guidelines. Annu Rev Pub Health 1997; 18:341-78.

17. Morris M, Lacopetta B, Platell C. Comparing survival outcomes for patients with colorectal cancer treated in public and private hospitals. Med J Aust 2007; 186:296-300.

18. The Royal College of Radiologists' Clinical Oncology Information Network. Guidelines on the non-surgical management of breast cancer. Version 1: June 1999.

19. Meyerhardt JA, Tepper JE, Niedzwiecki D, et al. Impact of hospital procedure volume on surgical operation and longterm outcomes in high risk curatively resected rectal cancer: findings from the Intergroup 0114 Study. J Clin Oncol 2004; 22:166-74.

20. Purves H, Pietrobon R, Hervey S, et al. Relationship between surgeon caseload and sphincter preservation in patients with rectal cancer. Dis Colon Rectum 2005; 48:195-204.

21. Schrag D, Cramer LD, Bach PB, et al. Influence of hospital procedure volume on outcomes following surgery for colon cancer. JAMA 2000; 284:3028-35.

22. McGrath DR, Leong DC, Gibberd R, et al. Surgeon and hospital volume and the management of colorectal cancer patients in Australia. ANZ J Surg 2005; 75:901-10. 